7 Hall N D, Gillan A H. Effects of antirheumatic drugs on protein sulphydryl reactivity of human serum. $J$ Pharm Pharmacol 1979; 31 : 676-80.

8 Jellum E, Munthe E, Guldal G, Aaseth J. Fate of the gold and the thiomalate part after intramuscular administration of aurothiomalate to mice. Ann Rheum Dis 1980; 39: 155-8.

9 Munthe E, Guldal G, Jellum E. Increased intracellular glutathione during penicillamine treatment for rheumatoid arthritis. Lancet 1979 ; ii: 1126-7.

\section{Synovial fluid in antiquity}

Sir, We enjoyed Dr Alarcon-Segovia's paper ${ }^{1}$ on the description of synovial fluid and therapeutic arthrocentesis by the Nahuatl Indians of Mexico in pre-Columbian times. We cannot agree, however, with the statement contained therein that Paracelsus is generally considered to be the first to have noted the presence of viscid liquor in the joint cavity. Numerous references to the existence of such fluid in the movable joints are found in the writings of the ancients, beginning with the Hippocratic texts Of the Places of Man and On the Articulations. ${ }^{2}$ Galen described the function of synovia as a joint lubricant in his treatise On the Function of the Parts of the Human Body, ${ }^{2}$ and in his commentaries on Hippocrates he stresses the importance of examination of the joint fluid: 'The physicians must examine the nature of the humor which, in a small quantity, envelops the joints, because many swellings of joints do not become purulent due to this humor. This, namely, is a thick humor. . . . Some physicians have already examined these swellings by incising them.'s

Much of the early information concerning joint fluid was derived from observations of traumatic injuries, and both Paracelsus and his followers, including Severinus (1542-1602), credit wound surgeons with the origin of the term synovia, which was also known by them as Gliedwasser (joint-water) and Gluttwasser (glow-water). ${ }^{2}$

Gerald P. Rodnan and Thomas G. BenedeK Division of Rheumatology and Clinical Immunology, Department of Medicine, University of Pittsburgh, Pittsburgh, Pennsylvania 15261, USA

\section{References}

1 Alarcon-Segovia D. Descriptions of therapeutic arthrocentesis and of synovial fluid in a Nahuatl text from prehispanic Mexico. Ann Rheum Dis 1980; 39: 291-3.
2 Rodnan G P, Benedek T G, Panetta W G. The early history of synovia (joint fluid). Ann Intern Med 1966; 65: 821-42.

3 Rodnan G P, Benedek T G. Hippocrates, Galen, and synovia. Ann Intern Med 1972; 76: 834-5.

\section{Venous thrombosis in SLE}

Sir, The article by Gladman and Urowitz ${ }^{1}$ confirmed a susceptibility to venous thrombosis of patients with systemic lupus erythematosus (SLE). Similar observations have been made by Peck, Hoffman, and Franck. ${ }^{2}$ Neither of these studies was able to define any specific characteristics which pre-disposed patients to venous thrombosis, although it is noteworthy that 3 of the 17 cases described by the former authors had a circulating anticoagulant. They did not state whether this feature was sought in every instance.

We have recently described 4 patients in whom recurrent or extensive venous thrombosis was associated with the presence of the lupus coagulation inhibitor. ${ }^{3}$ This paradox has been previously noted, ${ }^{4}$ and in our view is more than a chance association. In our cases further thrombosis was prevented by continuous warfarin treatment over an average period of 6 months. Interestingly, anticoagulation reduced the partial thromboplastin times and made it more difficult to demonstrate the inhibitor. There were no haemorrhagic complications during treatment. We believe that severe venous thrombosis in SLE should suggest the possibility of the lupus circulating anticoagulant, which, if demonstrable, is an indication for long-term anticoagulation.

\section{T. GiBson \\ Department of Rheumatology, Guy's Hospital, London SE1}

\section{References}

1 Gladman D D, Urowitz M B. Venous syndromes and pulmonary embolism in systemic lupus erythematosus. Ann Rheum Dis 1980; 39: 340-3.

2 Peck B, Hoffman G S, Franck W A. Thrombophlebitis in systemic lupus erythematosus. JAMA 1978; 240: 1728-30.

3 Williams $\mathbf{H}$, Laurent $\mathbf{R}$, Gibson $\mathrm{T}$. The lupus coagulation inhibitor and venous thrombosis: a report of four cases. Clin Lab Haematol 1980; 2: 139-44.

4 Bowie E J, Thompson J H, Pacuzzi C A, Owen C A. Thrombosis in systemic lupus erthematosus despite circulating anti-coagulants. J Lab Clin Med 1963; 62: 416-30. 